\title{
Grammatical Mistakes in College English Writing: Problem Analysis, Reasons and Solutions
}

\author{
LI Fengjie ${ }^{1}$, REN Jia ${ }^{2}$, ZHAO Hongyi ${ }^{1}$ \\ ${ }^{1}$ Foreign Languages Department, School of Humanities, Tianjin University of Finance and Economics, Tianjin, China \\ ${ }^{2}$ The Department of Linguistics and Translation, College of Liberal Arts and Social Sciences, City University of Hong Kong, China
}

Email address:

yyfx0901@163.com (LI Fengjie)

\section{To cite this article:}

LI Fengjie, REN Jia, ZHAO Hongyi. Grammatical Mistakes in College English Writing: Problem Analysis, Reasons and Solutions. International Journal of Applied Linguistics and Translation. Vol. 2, No. 3, 2016, pp. 20-28. doi: 10.11648/j.ijalt.20160203.11

Received: April 12, 2016; Accepted: June 24, 2016; Published: August 1, 2016

\begin{abstract}
In our modern society, English is used as an international language and communication tool, and it plays a more and more important role in the world. University students are regarded as the pioneers of modern information and it is self-evident that English is one of the important channels to get information. However, from the four basic skills of English -- listening, speaking, reading and writing, writing needs the most comprehensive knowledge, the strongest application, and the most difficult training. In order to find out the problems which exist in the cultivation of writing ability of college students, the author had a survey in an Experimental Class of Tianjin University of Finance and Economics in China trying to find out the problems college students encounter in English writing. The data have been gathered from the writing assignments of all the students in one term last year. The focus of this investigation is to analyze the grammatical mistakes in English writing, explore the systematic reasons and finally put forward some corresponding solutions to improve college English writing.
\end{abstract}

Keywords: College English Writing, Grammatical Mistakes, Reasons, Solutions

\section{Introduction}

In recent years, students have spent a lot of time and effort in learning English, and they have got unprecedentedly increasing input, which can greatly improve their reading and enlarge their vocabulary. However, in terms of output aspects such as students' writing and speaking competence, students do not have the obvious improvement. Writing is not only an important aspect of English learning, but also the embodiment of the comprehensive ability of using a language. According to the College English Curriculum Requirements (2007), the target of college English teaching is to develop students' comprehensive ability in English, so that students can use English in the future work and social interaction effectively. However, students' writing skills are currently far behind other English skills; in CET-4 and CET-6, the number of students who can reach the pass line are limited. Improving students' writing skills has become a problem that urgently needs to be solved in English teaching in China. For second language learners, a big problem in writing appears in the grammar of English, since writing strategies and methods have been influenced by the native language learning. If students can solve their problems of grammar, students' writing in English can achieve the level that is the same as the native language. With the rapid development of second language acquisition in our country, the author thinks that it is necessary to further study the grammatical problems in English writing, to analyze the reasons why there are difficulties in mastering grammar, and finally try to find solutions, so as to help students improve their writing ability.

In order to find out the common grammatical problems in college English writing, to improve college students' writing ability in English, and to minimize students' mistakes in the process of writing, the author first asks the students from an Experimental Class in Tianjin University of Finance and Economics in China to reply to a questionnaire the author has made to serve the purpose of the study, and then to analyze the grammatical problems which often appear in the process of writing, to explain the reasons for the students to make mistakes from the perspective of linguistics theory, in order to put forward the feasible measures finally. 


\section{Literature Review}

\subsection{Understanding Second Language Acquisition}

Sridhar (1981) points out that Error Analysis has a long tradition. Prior to the early 1970s, however, Error Analysis consisted of little more than impressionistic collections of 'common' errors and their linguistic classification (e.g French 1949). The goals of traditional Error Analysis were pedagogic -- errors providing information which could be used to sequence items for teaching or to devise remedial lessons. The absence of any theoretical framework for explaining the role played by errors in the process of SLA led to no serious attempt to define 'error' or to account for it in psychological terms. Also as the enthusiasm for Contrastive Analysis grew, the interest in Error Analysis declined. In accordance with Behaviourist learning theory, the prevention of errors (the goal of Contrastive Analysis) was more important than the identification of errors. It was not until the late 1960s that there was a resurgence of interest in Error Analysis. A series of articles by Corder (e.g. 1967; 1971; 1974) all traced this resurgence and helped to give it direction.

Error Analysis provides two kinds of information about interlanguage. The first is concerned with the linguistic type of errors produced by L2 learners. Richards (1974), for instance, provides a list of the different types of errors involving verbs (e.g. 'be'+ verb stem instead of verb stem alone -- 'They are speak French'). However, this type of information is not very helpful when it comes to understanding the learner's developmental sequence. Error Analysis must necessarily present a very incomplete picture of SLA, because it focuses on only part of the language L2 learners produce -- that part containing idiosyncratic forms. Describing interlanguage requires identifying what the learner can do by examining both idiosyncratic and non-idiosyncratic forms. Also because SLA is a continuous process of development, it is doubtful whether much insight can be gained about the route learners take from a procedure that examines language -- learner language at a single point in time. Error Analysis provides a synchronic description of learners' errors, but this can be misleading. A sentence may appear to be non-idiosyncratic (even in context), but may have been derived by means of an "interim" rule in the interlanguage. An example might be a sentence like "What's he doing?" which is well formed but may have been learned as a ready-made chunk. Later, the learner might start producing sentences of the kind 'What he is doing?', which is overtly idiosyncratic but may represent a step along the interlanguage continuum. For those reasons an analysis of the linguistic types of errors produced by learners does not tell us much about the sequence of development.

The second type of information -- which is relevant to the question about the strategies used in interlanguage -- concerns the psycholinguistic type of errors produced by L2 learners. Here Error Analysis is on stronger ground. Although there are considerable problems about coding errors in terms of categories such as 'developmental' or 'interference', a study of errors reveals conclusively that there is no single or prime cause of errors (as claimed by the Contrastive Analysis hypothesis) and provides clues about the kinds of strategies learners employ to simplify the task of learning a L2. Richards (1974) identifies various strategies associated with developmental or, as he calls them, 'intralingual' errors. Overgeneralization is a device used when the items do not carry any obvious contrast for the learner. For example, the past tense marker, '-ed', often carries no meaning in context, since pastness can be indicated lexically (e.g. 'yesterday'). Ignorance of rule restrictions occurs when rules extend to contexts where in the target language usage they do not apply. This can result from analogical extension or the rote learning of rules. Incomplete application of rules involves a failure to learn the more complex types of structure because the learner finds he can achieve effective communication by using relatively simple rules. False concepts hypothesized refer to errors derived from faulty understanding of target language distinction (e.g. 'is' may be treated as a general marker of the present tense as in 'He is speak French'). Perhaps the most ambitious attempt to explain SLA by analyzing the psycholinguistic origins of errors, however, is to be found in George (1972). George argues that errors derive from the learner's need to exploit the redundancy of language by omitting elements that are non-essential for the communication of meaning. Implicit in the types of analysis provided by both Richards and George is the assumption that at least some of the causes of errors are universal. Error Analysis can be used to investigate the various processes that contribute to interlanguage development.

The most significant contribution of Error Analysis, apart from the role it played in the reassessment of the Contrastive Analysis Hypothesis, lies in its success in elevating the status of errors from undesirability to that of a guide to the inner workings of the language learning process. As a result of interlanguage theory and the evidence accumulation from Error Analysis, errors were no longer seen as 'unwanted forms' (George 1972), but as evidence of the learner's active contribution to SLA. This contribution appeared to be broadly the same irrespective of differences in learners' backgrounds, suggesting that the human faulty for language may structure and define the learning task in such a way that SLA, like L1 acquisition, was universal in nature. However, the conclusive evidence -- proof that there was a natural route of development -- was not forthcoming from Error Analysis.

\subsection{Second Language Acquisition and Writing Teaching}

Despite all kinds of teaching methods have different names and priorities, their steps are more or less the same: 1 . Writing before the input; 2. More drafts before writing and 3 . Assignments marked -- the three basic stages.

\subsubsection{Writing Before the Input}

According to the theory of second language acquisition, firstly, the second language acquisition needs to have enough language input; Secondly, the learners' second language acquisition and use need the language learners' attention; finally, to study the second language acquisition contains both the learning of system rules and the accumulation of 
prefabricated language simultaneously. For the English writing teaching, these three points have the following corresponding enlightenment: 1) to strengthen the input, and to provide students with some real discourses which belong to the same genre as much as possible; 2) to guide the students to pay attention to the genre language structure and the language features, such as the adverbs that expresses the author's attitude; 3 ) to guide students to focus on the established lexical chunks, and to accumulate the genre writing such as academic writing and news writing .

\subsubsection{More Drafts Before Writing}

The theory of second language acquisition thinks that having the language knowledge is not the same as the use of language knowledge. Second language acquisition needs to have enough language output, and to know about yourself in the process of output gaps; Furthermore, second language acquisition has the process of automation and control, and the process of automation mainly comes from practices as many times as possible. Frequency effect plays an important role in the process of second language acquisition. In view of this, in the English writing teaching, teachers should design the writing task and topic that can stimulate students' interest in writing, in order to maintain the students' interest in writing and modifications. One draft has been modified for many times to consolidate the writing paradigm and skills on all kinds of genres, and to increase the output frequency of the phrase which is always used.

\subsubsection{Assignments Marked}

The theory of second language acquisition thinks that classroom teaching benefits for promoting foreign language and speeding up the acquisition, which is different from the state of nature or concomitant learning. According to that, teachers should circle the mistakes which students can modify by themselves, in order to raise the students' attention and then to correct mistakes independently. Then we can mark one student's assignments carefully, making comments and explanations on every mistake by students or by the teacher in the class; or to summarize some common mistakes in students' compositions, including structure, logical and grammatical mistakes. After that, we can design a lot of targeted exercises to consolidate learning of knowledge. In addition, mutual comments by peers is essential, through demonstration and guidance, let students know evaluation standard and methods clearly, and to learn how to correct their essays independently through modifying others' essays.

In summary, second language acquisition under the perspective of writing teaching strategies are as follows: 1) to stimulate students' interest through the design of task; 2) to read and input, to do some analysis and the accumulation of lexical chunks; 3) one draft needs to be modified for many times, and practice as much as possible; 4) to do correcting induction, classroom evaluation and mutual cooperation. When implementing these strategies, there are two key words: one is "frequency", that is the essential writing process which is through repeating many times, let the students read several essays from the same genre, to input and to output special lexical chunks from one genre, and to plan and to adjust to the idea for all the time. And for the teachers, students always make mistakes, which is also one common phenomenon in the process of learning. Another key word is "attention", that is, through specific teaching, let the students notice the genre model structure and the characteristics of phrase and sentence, the advantages of excellent essays, the individual mistakes in one's own essay, and pay attention to writing by readers as the center.

\section{The Questionnaire and Research Objects}

The subjects in the data are 18 sophomore students who come from an Experimental Class of Tianjin University of Finance and Economics. This questionnaire is aiming at finding out the feedbacks from four aspects, namely students' overall English level, their learning habits, problems in English writing and their chosen ways to improve writing skills.

The author first conducted a questionnaire directed to the students in this class, and made the questionnaire analysis. The following is the questionnaire results.

In general, the overall English Level of the students is brilliant through the analysis of the results from the questionnaire. In the first semester, all the students have got over- 80 scores in the intensive reading and extensive reading tests, while in the second semester, the figure declined a little but it remained over 80 . And the questionnaire shows that all the students in this class have passed the CET-4, and 13 students' scores are above 525, and the other 3 students' scores lies in 425-525; while in CET-6, 15 students have passed the exam with 6 of them scoring above 525, and 9 between 425-525. As for the vocabulary, 3 of them thought they have got above 7000, 5 between 5000 and 7000, 6 between 3500 and 5000 , and 4 below 3500 .

In the questionnaire, one question is "How many English compositions do you write in a week?" Nearly $85 \%$ of students said they only write 1or 2 compositions in a week, while others believed that they could finish 3 or 4 compositions. Another question is about the conversion between the English and Chinese, 10 of the students thought that when they write an essay, some sentences need to be finished in Chinese, and then translated to the English, while 5 students thought they seldom use this way to write an essay, and the rest 3 expressed they have never used this way before.

Concerning students' major problems in writing, grammar tops the whole list, while asked about the grammatical problems, about $83 \%$ of the students said that they never check the grammatical problems after finishing their essays. What's worse, they even won't summarize the grammatical problems after the teacher's correcting. Over $67 \%$ of students know a little about the English grammar, but no one wants to improve their grammar -- that's why the students think grammar is difficult.

From the feedbacks of the questionnaire, most students 
believed that practice is one way to improve their writing skills, while others thought that reading English novels or watching movies are better.

\section{Investigation and Analysis of the Common Grammatical Mistakes in College English Writing}

To write a wonderful essay means more than building up words without grammatical mistakes or misspellings. But no matter how complex the structure is, grammar is the first step. There are mainly three parts in English learning: pronunciation, vocabulary and grammar. The famous linguist Wilkins David. A (1972) said "Without grammar very little can be conveyed. Because vocabulary are some isolated parts. If you only have vocabulary but no grammar, the vocabulary is like the yellow leaves out of the trunk, they are lifeless."

As Wilkins said, grammar means laws in one language, and it gives the language an organized system, while the vocabulary is the material of language. Vocabulary gives language the specific content by grammar. So grammar is the centre of language.

The corpus for this paper was collected from the 18 students of one Experimental Class in Tianjin University of Finance and Economics. In the first term in the school year 2013 to 2014 , each of the 18 students wrote 8 compositions based on seven different ways of developing a paragraph. The topics for the compositions were as follows: 1) How to Prepare for a Picnic at the Weekend (development by process); 2) I Have Had a Happy School Life (development by time); 3) My Campus (development by space); 4) My Friends (development by classification); 5) Noise Pollution in the City Where I Live (development by example); 6) Over Development of Big Cities (development by cause and effect); 7) Popularity of Tours to Forests and Mountains (development by cause and effect); 8) Television and Cinema (development by comparison and contrast). For the convenience of error analysis, the author numbers the 18 students from X1 to X18, and the 8 compositions from $\mathrm{P} 1$ to $\mathrm{P} 8$ in accordance with the sequence above.

From the analysis of the corpus of college English writing, the author finds that the students have made a lot of grammatical mistakes. Those grammatical mistakes are classified by the following 10 kinds, namely 1 . Mistakes in nouns; 2. Mistakes in verbs; 3 . Mistakes in adjectives; 4. Mistakes in articles; 5. Mistakes in adverbs; 6. Mistakes in prepositions; 7. Mistakes in conjunctions; 8. Sentence fragments; 9. Subject-predicate disagreement; 10. Mistakes in the part of speech.

\subsection{Mistakes in Nouns}

Nouns are the most common part of speech in English. It can be used as subject, object, predicative and so on. Mistakes of nouns are almost the confusion of singular and plural nouns. Due to the differences between plural forms in Chinese and English, our English learners often make mistakes in their writings, especially those kinds of words that look like uncountable nouns but are actually countable ones. Take these following sentences for example.

Eg 1 (X5p6) Thus, it is high time that measure should be taken into effect.

In the dictionary, "measure" has several meanings. But only when it is used as "a unit used for stating the size, quantity or degree of sth.", it is an uncountable noun. In this sentence, the meaning of "measure" is obviously "an official action that is done in order to achieve a particular aim", so in this sentence it is a countable noun. The correct sentence would be as follows.

Thus, it is high time that measures should be taken into effect.

Let's take a close look at another example.

Eg 2 (X9p5) Everyday in the early morning my sweet dream are ended with the terrible noise rising up in the street.

In our mind, dreams are invisible, so some students take "dream" as an uncountable noun for granted. But "dream" is actually a countable noun. And in this sentence, he used "are" to be "dream's" verb, and he could not make sure that "dream" is whether an uncountable noun or not. If he could look it up in the dictionary, this problem is easy to be solved. The correct sentence would be as follows.

Every early morning my sweet dreams are ended with the terrible noise arising in the street.

Let's see another example. Some nouns should always be used as singular forms, but they express the plural meaning.

Eg 3 (X15p3) There're many ducks and fishes in it.

"Fish" is the common plural form, while "fishes" refers to some kinds of fish. Obviously, in this example, the author wants to express there are a lot of fish in their lake, not so many kinds of fishes. So one way of revising the sentence would be as follows.

There're many ducks and fish in it.

In conclusion, disturbed by the "Interlanguage interference", English learners will make some mistakes in nouns, which have some universality and regularity. Through the analysis of those mistakes, the author finds that sometimes students only pay attention to the sentences' expression, but ignore how to use nouns correctly. And it must be realized that those mistakes may make readers confusing, and twist the writer's original meaning.

\subsection{Mistakes in Verbs}

Verb usage errors can be classified by 5 kinds. They are: 1 . mistakes in the third person singular; 2 . mistakes in verb forms; 3. mistakes in modal verbs; 4. mistakes in the passive form; 5 mistakes in tenses.

\subsubsection{Mistakes in the Third Person Singular}

In high school, the verb conjugation on the third person singular has been learned. But there are always common mistakes in college English writing. Let's see these three examples.

Eg 4 (X4p2) ...because I has a really poor health.

Eg 5 (X4p6) It really do harm to the further development of the society. 
Eg 6 (X5p8) The way we watch films in a cinema give a chance to share happiness and sorrows with the audiences around us.

In the first example, "I" is not a "third person singular", so "has" should be replaced by "have"; but in the second example, "it" is a third person singular, the verb should be conjugated by "does". And in the third example, the subject is "the way", "we watch films in a cinema" is an attributive, so the subject is obviously "third person singular", the verb should be conjugated by "gives". The three examples show that although the verb conjugation is easy to learn, when writing essays students often make mistakes. Reasons for that may be various.

1. Students are careless when writing in English.

2. The attributive after subject may be too long and it confuses the writer to use the wrong verbs.

In conclusion, that kind of mistake is a basic one in verbs' using. But it still needs our attention.

\subsubsection{Mistakes in Verb Forms}

This type of mistake is quite obvious in students' essays. For example, the right form is "enjoy doing sth", and "enjoy to do sth" is a wrong expression. Now let's take a look at one example.

Eg 7 (X2p5) Lastly, I just want to appeal every student to reduce the noise from our daily behavior.

The fixed collocation is "appeal to sb to do sth", because "appeal" in this sentence is an intransitive verb, so the verb should be followed by "to" to have an object. So the correct sentence should be as follows.

Lastly, I just want to appeal to every student to reduce the noise from our daily behavior.

Let's see another example.

Eg 8 (X5p2) Run steady relationship became one of the things in my campus life.

That is not an imperative sentence, so "run" should choose a gerundial form or infinitive form to express the habitual action. The correct sentence should be as follows.

Running steady relationship became one of the things in my campus life.

Eg 9 (X7p3) Sometimes you can see a group of ducks swimming and bask in the sun.

Parallel structure not only can make sentence well-proportioned, but also can act as bond which can combine discourses. But the student who like using this structure often ignores one thing, that is, the elements combined by "and" must be the same verb form. So one way of revising this sentence would be as follows.

Sometimes you can see a group of ducks swimming and basking in the sun.

\subsubsection{Mistakes in Modal Verbs}

In English, there are a lot of verbs which can express people's mood. And the verbs are called modal verbs. The author finds that students can not use modal verbs in a right way. Let's have a look at one example.

Eg 10 (X8p8) Watching TV may can't bring that atmosphere in cinema.
"May", "can't" are both modal verbs, and the two words could not be used together in this sentence, so the correct sentence is as follows.

Watching TV may not bring that atmosphere in the cinema.

\subsubsection{Mistakes in the Passive Form}

A standard passive sentence's form is "sth. + be + past participle + by $+s b$ ". If the subject has been referred to in the previous sentence, it can be omitted in the next. But students always use the past participles in a wrong way. Let's take an example for a look.

Eg 11 (X5p1) Sausages, bacon, chicken, French fries and some high caloric food would be prefer in a picnic.

This sentence's object is "Sausages, bacon, chicken, French fries and some high caloric food", and "would be" is part of the predicate, "prefer" should choose the past participle form "preferred" in a passive voice, so one way of revising the sentence is as follows.

Sausages, bacon, chicken, French fries and some high caloric food would be preferred in a picnic.

\subsubsection{Mistakes in Tenses}

Due to differences on tenses between the Chinese and English, the concept of tense is not in the mind of Chinese students, so when using tenses in the writing, it is easy to cause confusion and make mistakes in tenses. An example is provided as follows.

Eg 12 (X1p2) I have come across my best friends and I got a lot of knowledge.

In this sentence, "and" is used as a conjunction, and its basic function is like a bridge. The verbs' tense on both sides should be consistent. The tense of the first clause is the present perfect, but the second behind "and" is the simple past. No doubt the clause is behind "and" should also use the present perfect. And it would be better if changed in this way.

I have come across my best friends and I have got a lot of knowledge.

How to use tenses in certain circumstances is difficult for English learners. For example, differences between the present perfect and simple past always confuse English learners. Let's have a look at this example.

Eg 13 (X12p5) The gunpowder already recognized this problem very important now.

In this sentence, "already" is a symbol of the perfect tense, and this sentence means to express the problem which took place in the past has an influence today. To use the present perfect would be better in this sentence. One way of revising this sentence is as follows.

It has already been recognized that the gunpowder is very important now.

When we first learn the past participles, we have to remember some irregular verbs. Some students are still confused by whether a word has a regular form or not. Let's see the first example.

Eg 14 (X2p2) I just hearded: "Stop! Stop!"

Obviously, "hearded" is a word which is created by this student. The past tense form of "hear" should be "heard". So the correct sentence should be as follows. 


\section{I just heard: "Stop! Stop !"}

Next, let's see an example that the student takes a regular verb as irregular by mistake.

Eg 15 (X8p6) The development of cities, as I see it, has bestow us enormously benign benefits.

"Bestow" is a verb with regular form in the past tense, so the correct form of the past participle should be "bestowed", and the correct sentence should be as follows.

The development of cities, as I see it, has bestowed enormously benign benefits on us.

From this example, we could get a conclusion that some words which we don't use frequently should be given enough attention to, especially their past participle should be remembered firmly.

\subsection{Mistakes in Adjectives}

The adjective is an open part of speech, mainly used as a modifier in the sentence. When using adjectives, a phenomenon that can't be avoided is the change of adjectives in the comparative and superlative degrees. So mistakes in adjectives are mainly those on the form of comparative adjectives. Let's see an example.

Eg 16 (X12p8) Going to cinema is much expensive than watching TV.

In this sentence, "much" is not correct in this sentence, because "expensive" is a multi-syllable word, so the comparative form is "more expensive". One way of revising the sentence is as follows.

Going to the cinema is more expensive than watching $T V$.

And another way of revising the sentence is as follows.

Going to cinema is much too expensive compared with watching $T V$.

\subsection{Mistakes in Articles}

Articles are the unique part of speech in English, consisting of indefinite articles, "a", "an", and definite article "the", and zero article. Although articles always emerge in the passages, articles are difficult for the language learners, especially those whose language systems do not have some words like articles. Mistakes in articles can be classified by three kinds: 1 . Mistakes in lack of articles; 2. Multi-purpose articles 3. Misuse in articles.

\subsubsection{Mistakes in Lack of Articles}

Eg 17 (X10p3) My school is graceful and quiet place.

"Place" is a countable noun, so it needs an article to modify "place". In the word "graceful" the first letter is pronounced /g/, so the article before it should choose "a". The correct sentence would be as follows.

My school is a graceful and quiet place.

\subsubsection{Multi-purpose Articles}

Eg 18 (X2p7) Nowadays, having tours to forests and mountains has become $a$ popularity among the public.

In this sentence, the student wants to express tours to forests and mountains has become more and more popular among the public. So "a" has no means in this sentence; Furthermore, "popularity" is an uncountable noun, to use "a" is also inappropriate. Based on the two aspects the correct sentence should be as follows.

Nowadays, having tours to forests and mountains has become popular among the public.

Let's see another example.

Eg 19 (X17p2) School life is an important in my life.

"Important" is an adjective, after "important" there is no center. So the structure is " $\mathrm{S}+\mathrm{V}+\mathrm{C}$ ", that is, "important" is the predicative, not an object, so the article "an" is not needed. The correct sentence should be as follows.

School life is important in my life.

\subsubsection{Misuse in Articles}

Misuse in articles means the confusion of differences between "a" and "an". When the word's first letter is a vowel phoneme, the article which modifies the word should be "an". But if it starts with a consonant, the article should select "a". Let's see an example.

Eg 20 (X2p2) I turned my head around, saw an boy who ran to me as shouted anxiously.

"An" is usually to modify nouns whose first phoneme is a vowel, but in the word "boy's" the first sound is " $/ \mathrm{b} /$ ", a consonant, not a vowel phoneme. So the correct sentence would be as follows.

I turned my head around, saw a boy who ran to me, shouting anxiously.

Let's have a look at another example.

Eg 21 (X14p2) For us, school is a place where we are educated to be a civilized man and learned man out of $a$ innocent child.

In this sentence, "a" is used to modify "innocent", but in "innocent" its first letter is " $\mathrm{i}$ ", pronounced /i/, so it is a vowel phoneme. The article "an", not "a" should be used before it. The correct sentence would be as follows.

For us, school is a place where we are educated to be a civilized man and learned man out of an innocent child.

For English learners in Chinese, to master articles is a bit difficult, because its usage is complex and variable; there are often mistakes in articles. Maybe practice is the best way to master articles.

\subsection{Mistakes in Adverbs}

Adverbs are mainly used to modify verbs, adjectives, adverbs, or other structure. Take the following sentence as an example.

Eg 22 (X10p4) However, they can still quite help me when needed.

"Quite" is an adverb, but it is very special. It can not only modify adjectives, adverbs and verbs, but also can modify nouns and prepositional phrases, etc. But in this sentence "quite help" seems a little strange. The correct version should be as follows.

However, they can still help me a lot when needed.

\subsection{Mistakes in Prepositions}

How to use the prepositions in a right way is difficult for 
English learners, so mistakes in prepositions is a common phenomenon. Next let's have a look at the examples.

Eg 23 (X2p2) We were so excited for having a chance to fly kites with classmates at the end of our primary school's life.

"Excited" is always collocated with the preposition "at" "about" and "by". So "be excited for" is not as natural as the other three fixed collocations. The correct sentence would be as follows.

We were so excited at having a chance to fly kites with classmates at the end of the day in our primary school.

Eg 24 (X2p5) In the public, people should pay more attention on their behavior such as speaking voice and laughter.

"Pay attention to sth" is the most common fixed collocation in our writing essays. But in this example, the student used "on" instead of "to". The fixed collocations are conventional. So this sentence would be better.

In the public, people should pay more attention to their behaviors such as lowering their volume in speaking or laughing.

Reasons for the mistakes in prepositions mainly result from the interference of the native language. In Chinese, we do not have so many prepositions as in English. So English learners are usually confused by the usage of prepositions. To remember some fixed collocation is a better way to help students make out the usage of prepositions.

\subsection{Mistakes in Conjunctions}

The phenomenon of mistakes in conjunctions is relatively common. Generally speaking, one of the causes for mistakes is that the students do not understand the sentence structure. When the subject, the predicate and other ingredients such as the adverbial and the complement are included in the sentence, the sentence should be ended with a period, or by conjunction connecting two small clauses before and after. Some students don't know that. In their opinion, what they want to express has not been finished, so they just separate sentences by a comma, then the sentence structure is wrong.

Eg 25 (X17p2) We could do everything we like at will and didn't have to worry about grades, scold from teachers.

In this sentence, the student first uses "scold" as a noun by mistake, "scold" should be replaced by "scoldings", then "from teachers" is actually to modify "scoldings", so it is a noun, not a clause, the comma should be replaced by a conjunction "and". This sentence would be better corrected like this.

We could do everything we like at will and didn't have to worry about grades and scoldings from teachers.

\subsection{Sentence Fragments}

Sentence fragments are one of the most serious grammatical problems. In certain cases, the subject or the object can be omitted while most probably the predicate is necessary. But some students do not grasp the knowledge in a proficient way. As a result, some predicates which are essential in the sentences are omitted by students. For example:
Eg 26 (X2p2) As time goes by, I have been of ages, and now I a freshman.

The last clause is an obvious structure -- $\mathrm{S}+\mathrm{V}+\mathrm{O}$, "I" is the subject, "freshman" is the predicative, "a" is an article that modifies the predicative. But in this sentence the verb is omitted, so this sentence looks incomplete. The correct sentence would be as follows.

As time goes by, I have been of age, and now I am a freshman.

Let's have a look at another example.

Eg 27 (X10p5) Teaching the factories not to be under construction one of the simple examples.

This sentence is a little longer than the first example. But when we divide this sentence by its elements, we can easily find that "Teaching the factories not to be under construction" can serve as the subject of this sentence, and "one of the simple examples" the predicative, but the verb is still lost. The correct sentence would be as follows.

Asking the factories not to be under construction is one of the simple examples.

From that example, we could find that no matter how long the sentence is, if we can divide the sentence in a right way, this kind of mistakes can be minimized. Let's look at the next example which lacks the object.

Eg 28 (X12p2) Everyone said that he is a bad guy and warned not to be so closed with him.

In the dictionary, "warn" is often used in a fixed phrase "warn sb not to do sth", but in this example, the object behind "warned" is missing, so the correct sentence would be as follows.

Everyone said that he is a bad guy and warned me not to be so close to him.

Sentence fragments are usually manifested as lack of predicates, and the researchers believe that the reason for mistakes is that students can not divide one sentence by its elements in a right way. One sentence needs a predicate, and a predicate can be a verb, either "be" or a notional verb. Besides the predicate, a sentence also needs a subject, which is generally acted by nouns, pronouns, or a clause. The subject and the predicate are the basic elements in one sentence. The most common sentence structure is subject + predicate. In the process of writing, students tend to only consider the semantic needs, but ignore the grammar rules. It is one common phenomenon that two or more than two predicates or subjects have been used in one sentence, or there is no predicate or subject in a sentence at all. Researchers believe that ignoring the basic elements in the grammar teaching can lead to serious grammar mistakes in students' writing. The basic element in the grammar teaching is very important.

\subsection{Subject-Predicate Disagreement}

Subject-predicate disagreement mainly manifests as that subject do not suits the predicate's form in number. For example, the subject is not the third person singular, like "I", but the predicate is "has". Let's have a look at one example.

Eg 29 (X1p3) We thanks for him.

In this sentence, "we" is the subject and "thank" is the 
predicate. However, this student uses "thanks". It is obviously wrong that "we" is not the third person singular, but "thanks" is the predicate's third person singular. The correct sentence would be as follows.

We thank him for what he has done.

From this example, the subject-predicate agreement seems simple, but actually it is not so easy to use, and sometimes it is very complex. That is because different situations need different rules to apply. In terms of its basic principles in modern grammar, there is usually a focal point of the three different angles: 1. Grammar Concord; 2. Notional Concord; 3. Principle of Proximity.

\subsection{Mistakes in the Part of Speech}

In English writing, some students often make mistakes in the part of speech. For example, "success" is a noun; while "succeed" is a verb; "successful" is an adjective. And some words still need our enough attention. Now, let's see an example.

Eg 30 (X13p1) And also you must choice a sunny day.

"Choice" is a noun, and some students may take it as a verb. The right word is "choose". And in this sentence a verb is needed, so "choice" should be replaced by "choose". The correct sentence should be used as follows.

And also you must choose a sunny day.

Mistakes in the part of speech are a fundamental problem. So, when we master words, we should not only pay attention to their spelling, but also take notice of their parts of speech.

\section{The Reasons for Grammatical Mistakes in College English Writing}

The study finds that college students will make mistakes in grammar in English writing, especially in the use of verbs.

\subsection{Mother Tongue Interference}

In Chinese, the predicate does not need to change its form; While in English the form of the predicate changes so much. In English, If we want to say something is happening, we should use "be + verb + ing". If we want to express something happening in the past, we should use the past tense. All in all, people need to use different tenses to express something happening in different times. In Chinese, we just change temporal adverbials to express something that happens in different times. Besides, there are some differences on the verb's meaning between English and Chinese, so it is easy for students to make mistakes in using verbs in English writing. English is the second language for most Chinese, so the native language will inevitably have some unconscious influence on using English. It is quite common for students to carry the Chinese grammar to English writing. When the Chinese-English word order is consistent, this is a positive transfer. But when the Chinese-English word order phase asynchrony, the mother tongue will interfere with the using of English, the negative transfer emerges.

\subsection{Differences in Cultural Backgrounds}

It is generalized that the thinking way of the Chinese is circular, while the English linear. Reflected in writing, the English speakers often come straight to their points, then demonstrate their points step by step.

The differences on cultures result in the different ways of thinking between Chinese and English-speaking speakers, so it is easy to paraphrase the native culture into English. As a result, mistakes on grammar emerge. Therefore, different cultures have big influence on using the different languages.

\subsection{Incomplete and Unsystematic English Knowledge}

There are lots of spelling errors in students' English writing, which shows that students have an inadequate amount of vocabulary. Students should spend more time in enlarging words. At the same time, it is also necessary to learn how to use these words. And the so-called overgeneralization is to apply the knowledge which we have learned and summarized to the situations beyond rules, leading to wrong usage. For example, due to not well-grasping the predicate verb, after learning "want to do, go to do, come to do, hope to do, etc", then put "enjoy doing, finish doing, mind doing" summarized as "enjoy to do, finish to do, mind to do", which are totally wrong.

\section{Solutions to the Grammatical Problems in College English Writing}

Through the analysis of the mistakes in college students' English learning, the author thinks that we can help students to minimize mistakes through the following two aspects.

First of all, a lot of English grammatical mistakes are interlingual transfer mistakes. Second language learners' language should be regarded as an internal language system, and it is the interlanguage between the first language and the second language. Selinker (1969) thought that learners built their own intermediary language structure through language transfer, intralingual transfer, transfer of training, foreign language learning strategies, foreign language communication strategy and other means.

Chinese students' foreign language learning process is a kind of new knowledge learning process. With the help of teaching means to acquire the language knowledge and ability, most learners learn a foreign language through class activities. The interlanguage system which is established through this process can not be so complete and natural as a mother tongue. When they can't use the target language effectively, native language knowledge is used to fill the void, and the interlingual transfer will happen. It has a lot of inspiration for college English teaching. If teachers can combine the language comparison, mistake analysis and cultural comparison and language acquisition organically, then it can help students to use the known knowledge to realize the positive transfer of Chinese thinking to the English thinking effectively. Therefore, the teacher should pay more attention 
to the discourse analysis of the text. If more contrastive analysis of Chinese and English can be introduced in the first two semester in college, it will consolidate the students' ability of using English grammar knowledge.

Second, from the intralingual transfer mistakes, the author finds that students do know some of the rules of grammar. If the grammar took place in the form of multiple choice, most of the students will not have any difficulty. Thus, the nature of the problem lies in the lack of actual practice. Sharwood Smith (1942) said that learners who have focused on grammar directly and have had a lot of opportunity to use grammar linking to the language environment are more likely to put the rules of grammar in long-term memory. College students' mistakes in English grammar exposed the weakness that college English grammar teaching does not have enough practice to cooperate with that. In this sense, practice does not mean that teaching material often appears as exercises, such as multiple choices, filling in the blanks, and other boring practices. In contrast, it is close to the actual output of speaking or writing practice. Therefore, English teachers should design some practice which is around the key grammar phenomenon through English grammar teaching, so that the students can learn grammar for actual use. In this way, the grammar knowledge will leave a more lasting imprint in the students' mind.

\section{Conclusion}

By using error analysis, the author finds that the students' mistakes have certain regularities, and the English teachers should adopt some effective teaching strategies in teaching to help students reduce or even avoid mistakes and call on students' attention to cultivating grammar skills.

The first thing is to strengthen the guidance of students' learning strategies. One of the important tasks of English courses is to make sure students develop some good writing habits. Teachers should consciously strengthen the guidance of students' learning strategies, let them learn and use English grammar step by step through the learning process.

The second is to strengthen the comparison and analysis of the native language and target language, pay attention to guiding students to think in English, make practice for the key sentence patterns, tenses, voices and other major language phenomenon as many times as possible, and this will stimulate students' brain constantly. It is an effective way to overcome Chinese sentence pattern interference.

Using modern education technology is an important channel for students to learn and use English. Using the modern education technology can help students input a large amount of information in a natural way. In grammar teaching, we used to adopt deduction, induction, comparison and other methods. To some extent we should change the teaching methods now, putting grammar knowledge in the context of teaching appropriately, to make students participate in the analysis of grammatical phenomena, to raise students' ability of summarizing and using English. This kind of teaching mode can improve the students' interest in learning, and it also can better teaching effect for students.

\section{Acknowledgements}

The work is supported by the Teaching Research and Reform Project in Tianjin University of Finance and Economics in China in 2015(No. JGY2015 - 15), and The Project of Teaching Reform on the academic degrees and Postgraduate education in 2014 in Tianjin University of Finance and Economics in China (No. 2014YJZ11).

\section{References}

[1] Brooks, N. (1960). Language and Language Learning. New York: Harcourt Brace and World.

[2] Cheng, J. (1994). On the teaching of English writing. Foreign Language Teaching and Research, 98 (2): 12-18.

[3] Connors, R. J. (1981). The rise and fall of the modes of discourse. College Composition and Communication 34, pp. 444-455.

[4] George, H. 1972. Common Errors in Language Learning: Insights from English. Rowley, Mass.: Newbury House.

[5] Krashen, S. 1998. Writing: Research, Theory and Application. Oxford: Pwegamon Press.

[6] Liu, M. and Wang, G. (2011), Paragraph-level Errors in Chinese Undergraduate EFL Learners' Compositions: A Cohort Study, Theory and Practice in Language Studies, Vol. 1, No. 6, pp. 584-593.

[7] Langman Dictionary of Contemporary English. (2004). Beijing: Foreign Language Teaching and Research Press.

[8] Richards, J. (ed.). 1974a. Error Analysis. London: Longman.

[9] Richards, J. (ed.). 1978. Understanding Second and Foreign Language Learning. Rowley, Mass.: Newbury House.

[10] Rod, E. (1985). Understanding Second Language Acquisition. Oxford University Press.

[11] Sun, J. (2010). A Corpus-based Study of Errors in Chinese English Majors' English Writing. Asian Social Science, Vol. 6, No. 1.

[12] Tomlinson, B. (1998). Introduction. In Tomlison, B (Ed.), Materials Development in Language Teaching. Cambridge University Press.

[13] Wilkins, D. A (1972). Linguistics in Language Teaching. MA: MIT Press. 